\title{
Jealousy and commitment: Perceived threat and the effect of relationship alternatives
}

\author{
ROBERT J. RYDELL,${ }^{a}$ ALLEN R. MCCONNELL,${ }^{a}$ AND ROBERT \\ G. BRINGLE ${ }^{b}$ \\ ${ }^{a}$ Miami University and ${ }^{b}$ Indiana University-Purdue University Indianapolis
}

\begin{abstract}
Most research on jealousy has focused on the correlation between one psychological factor and jealousy. In contrast, the current work examined how the link between relationship commitment and jealousy depends on the interplay of two situational factors: attractiveness of relationship alternatives and receiving threatening information about the self and the romantic relationship. In two studies, participants completed measures of relationship commitment for their current relationship and then received feedback that manipulated their perceptions of relationship alternatives (Study 1) or their perceptions of relationship compatibility (Study 2). Participants' jealousy was assessed by their responses to a mildly threatening relationship situation (Studies 1 and 2) and on a jealousy scale (Study 2). Study 1 showed that those in more committed relationships experienced greater jealousy when they were induced to consider having unattractive relationship alternatives. Study 2 showed that those with greater relationship commitment reported more jealousy when they received negative information about their relationship compatibility. Implications for how threat plays a causal role in experiencing jealousy are discussed.
\end{abstract}

Numerous factors have been proposed to explain when and why jealousy occurs. Personality variables such as neuroticism and obsessiveness (e.g., Buunk, 1997), relationship factors including love and dependence (e.g., Buunk, 1991), evolutionary pressures that emphasize inclusive fitness goals (e.g., Buss, 2000), and contextual, cultural, or social situational variables (e.g., Hupka, 1991) have all received somewhat modest support in their ability to predict jealousy. The current work argues that a clearer understanding of jealousy emerges by considering how such factors interact with each other.

Correspondence should be addressed to Robert J. Rydell, Miami University, Department of Psychology, Oxford, OH 45056, e-mail: rydellrj@muohio.edu.

This research was supported by NIMH Grant MH60645 and MH68279. The authors thank Eli Finkel, Mike Gray, Steve Rholes, and Susan Sprecher for their helpful comments on this research. We appreciate the helpful contributions of Stacy Eppley, Emma Hutter, Chris Jones, Kim Palmer, Kristal Reis, Minya Smith, and Courtney Snyder in conducting these experiments.
White and Mullen (1989) define jealousy as, "A complex of behaviors, thoughts, and emotions resulting from the perception of harm or threat to the self and/or the romantic relationship by a real or potential rival relationship" (p. 54). This definition implies that each of these factors, and how it affects perceptions of threat, is potentially important in understanding jealousy. In line with this definition, most theoretical conceptualizations of jealousy propose a rich integration of these different factors (e.g., Salovey, 1991; White \& Mullen). For instance, White and Mullen's and White's (1991) systems theory interpretation of jealousy posits that the commitment of the current relationship interacts with other factors (e.g., the relationship between the rival and the jealous person) to facilitate the expression of jealousy. Similarly, Bringle (1991) predicts that situational factors, relationship factors, and personality factors interact to facilitate the expression of jealousy.

A considerable amount of research on jealousy has focused on the level of relationship 
commitment and how individuals feel about themselves in their romantic relationships (e.g., Bringle, 1991; Buunk, 1991; White \& Mullen, 1989). For example, it has been demonstrated that constructs examining the interdependence of the romantic relationship (e.g., dependency, investment, satisfaction, comparison level of alternatives [CLalt], commitment) are important correlates of jealousy (e.g., Bringle; Buunk; White, 1981; White \& Mullen). Although this research has been important for theoretical conceptualizations of jealousy (e.g., Buunk), most (if not all) of this research is correlational and none of it examines the processes that underlie the association between jealousy and commitment or explores possible moderators of this relation. A correlational approach is a reasonable first step in understanding the relation between perceptions of relationship commitment and jealousy because greater perceptions of commitment should be related to greater distress in response to a jealousy-evoking event. Indeed, the literature on jealousy has generally supported this supposition (e.g., Buunk, 1982, 1991; Buunk \& Bringle, 1987; Mathes, 1986; Mathes \& Severa, 1981; White, 1981).

However, looking only at how factors within the relationship (i.e., commitment) relate to jealousy may not fully account for jealous responses (e.g., Bringle, 1991; DeSteno \& Salovey, 1996; White \& Mullen, 1989). Instead, the current work proposes that examining the interplay of factors internal and external to the romantic relationship using experimental manipulations can speak to the causes of jealousy more clearly and more directly. Thus, in an effort to extend previous correlational research, the current studies examined the interaction of situational conditions and relationship commitment in the expression of jealousy. It was posited that as situations are perceived to be more threatening to the relationship and to the self, individuals in more committed relationships would experience greater jealousy.

\section{Commitment}

Rusbult's (1980, 1983) Investment Model contends that the most important aspect of a romantic relationship is its level of commitment. In the Investment Model, commitment is defined as the experience of relying on a romantic relationship to fulfill important interpersonal and intrapersonal needs (Agnew, Van Lange, Rusbult, \& Langston, 1998; Le \& Agnew, 2003; Rusbult, Martz, \& Agnew, 1998). Relying on a relationship for fulfillment has many consequences, most notably, the intention to stay in the current relationship (e.g., Rusbult, 1983) and the reduced likelihood of infidelity (Buss, 2000). Indeed, perceptions of relationship commitment are important in understanding individuals' perceptions of their romantic relationships (e.g., seeing the relationship from a "we" perspective as opposed to an "I" perspective; Agnew et al., 1998), relationship interactions (Johnson \& Rusbult, 1989), and determining when relationships will prosper or fail (Rusbult, 1983). Rusbult (1980) found that relationship commitment was associated with increasing levels of relationship satisfaction, investment, and the degree to which outcomes from the present relationship exceed expected outcomes from an alternative relationship or no relationship at all (CLalt). Commitment is also important for how romantic relationships function, how individuals perceive their relationship partner's actions, and how relationship distress is handled (e.g., Rusbult, Verette, Whitney, Slovik, \& Lipkus, 1991).

\section{Threat and jealousy}

Perceptions of threat are also important to understanding when a person is likely to experience jealousy (e.g., DeSteno \& Salovey, 1996; Sharpsteen, 1995). As White and Mullen (1989) note, this threat can come from two sources: threat to the self or threat to the relationship. Threats to the self include threats to one's self-esteem or a valued aspect of the self (DeSteno \& Salovey). Threats to the relationship include threats that are specific to the investments put into a particular romantic relationship. Although it has been found that the general appraisal of threat is most important for facilitating the experience of jealousy (Sharpsteen, 1995), it is likely that certain situations may lead to perceptions of threat in only one 
domain (relationship or self) and still facilitate jealousy (e.g., DeSteno \& Salovey, 1996).

Research focused on examining the interplay of threats to the self and threats to romantic relationships has shown that people who perceived greater threat to the self and greater threat to the relationship reported more jealousy than people who received only one type of threat (Sharpsteen, 1995). ${ }^{1}$ Because it was predicted that relationship threat and self threat would both be important to more fully understanding the relation between commitment and jealousy, the current research focused on understanding the role of overall threat in facilitating jealousy and not on distinguishing the role of different types of threats and jealousy.

In the current work, two studies were conducted to examine if having a more committed relationship leads to greater jealousy. The level of threat in each study was experimentally manipulated to examine causal relations and establish boundary conditions for past findings that perceptions of threat and perceptions of relationship commitment are related to jealousy. Study 1 manipulated threat by increasing the accessibility of attractive or unattractive relationship alternatives. Study 2 manipulated threat directly by providing false feedback about relationship compatibility. If jealousy is facilitated by perceptions of threat and individuals in more committed relationships experience more threat in response to jealousy-evoking situations, relationship commitment should be positively related to jealousy when perceptions of threat to the self and relationship are induced. When no threat is perceived, the positive relation between relationship commitment and jealousy should be attenuated.

\section{Study 1}

One important situational factor affecting jealousy is the attractiveness of relationship alternatives (e.g., Hansen, 1991; Shettel-Neuber,

1. Unfortunately, little work has been done on distinguishing threat to the self from threat to the relationship (e.g., DeSteno \& Salovey, 1996; Sharpsteen, 1995; White \& Mullen, 1989).
Bryson, \& Young, 1978). Even when in a committed relationship, individuals monitor possible alternatives to their current relationship, and this knowledge influences interactions with their current partner (e.g., Buss, 1994, 2000; Buunk, 1991; Kelley, 1979; Thibaut \& Kelley, 1959). If relationship alternatives are unattractive, individuals should rely more heavily on their current relationship for positive relationship outcomes. However, if relationship alternatives are attractive, individuals should not rely as heavily on positive outcomes from the current relationship because they could receive comparable positive outcomes from an alternative relationship (Kelley). Because attractive relationship alternatives are those that offer relatively more positive outcomes compared to the current relationship, individuals in more committed relationships should experience less jealousy in response to a jealousy-evoking situation when attractive alternatives are accessible.

Several theories of jealousy predict that relationship commitment and the attractiveness of relationship alternatives should interact to facilitate the expression of jealousy because to the extent that individuals are more committed to their relationship and perceive that they have unattractive dating alternatives, a jealousy-evoking situation should be perceived as especially threatening to the self, to the relationship, and to the emotional, temporal, and material investments put into the relationship (e.g., Bringle, 1991; Bush, Bush, \& Jennings, 1988; Buunk, 1991; Hansen, 1991; Radjecki-Bush, Farrell, \& Bush, 1993; White, 1981, 1991; White \& Mullen, 1989). Although men and women react differently to threat, evolutionary theory predicts that cognitive mechanisms are activated when a romantic relationship is threatened (e.g., Buss, 2000). Specifically, men and women are sensitive to different types of threats to fidelity (emotional or sexual) that could reduce the resources necessary for their offspring.

Indeed, correlational data suggest that as individuals are more committed in relationships, they perceive more threat in jealousyevoking situations (e.g., Buunk, 1991; White, 1981). But even though many theories 
suggest that individuals who perceive more threat to their relationship or self and perceive greater relationship commitment experience more jealousy (e.g., Bringle, 1991; White \& Mullen, 1989), no experiment has examined how commitment and the attractiveness of relationship alternatives jointly affect the expression of jealousy. Decreasing the attractiveness of relationship alternatives should result in more threatening appraisals of jealousy-evoking situations, whereas increasing the attractiveness of relationship alternatives should decrease amount of threat perceived in jealousy-evoking situations (e.g., Bush et al., 1988; Buunk; Kelley, 1979; Radjecki-Bush et al., 1993; Shettel-Neuber et al., 1978; White, 1981); however, these appraisals should depend on the level of commitment in the current romantic relationship (e.g., Bringle, 1991; Buunk, 1991; White, 1991; White \& Mullen, 1989). Specifically, individuals in more committed relationships who perceive having unattractive relationship alternatives should react more jealously when their relationship is threatened because their stake in the current relationship is especially large and their alternatives are unappealing.

\section{Method}

\section{Participants}

At Miami University, 59 students (42 women and 17 men, with a mean age of 18.72 years and a mean relationship duration of 13.64 months) participated in the research to fulfill a course requirement. All participants were involved in a serious romantic relationship (i.e., a monogamous relationship lasting at least 3 months) at the time of the study. Neither gender nor relationship length moderated the effects observed in the current studies, thus they receive no further attention.

\section{Commitment and CLalt}

Measures of relationship commitment and CLalt were measured by administering the commitment and CLalt subscales of the Investment Model Scale (Rusbult et al., 1998). Participants rated 11 items (6 items for com- mitment and 5 items for CLalt) on a 9-point scale ranging from 0 (not agree at all) to 8 (agree completely), with greater scores indicating greater commitment to the relationship (e.g., "I feel very attached to our relationship — very strongly linked to my partner.") or greater CLalt (e.g., "If I weren't dating my partner I would be doing fine-I would find another appealing person to date."), respectively. These scales have been shown to have high reliability and convergent validity (Rusbult et al., 1998), and the commitment scale and the CLalt scale were both reliable in the current study $(\alpha=.94$ and $\alpha=.96$, respectively).

\section{Manipulating the attractiveness of relationship alternatives}

To manipulate the attractiveness of relationship alternatives, participants were first asked to visualize themselves in one of three situations and then to write a description of the type of person that they would date if they were in that situation. In the increase attractiveness of alternatives condition, participants visualized themselves in the following situation:

Imagine that you are dating your ideal romantic relationship partner (but not your current partner). This person epitomizes everything that you have been looking for in a partner. This partner could be real or fictitious, what is important is that they are the person you feel would be the best partner for you in a romantic relationship. They would be perfect for you in every way.

In the decrease attractiveness of alternatives condition, participants visualized themselves in the following situation:

Imagine that you could not attract anyone romantically (even your current partner would not find you attractive). Even people that you would normally attract, but that you find unattractive yourself, would not date you. You spend many lonely nights at home longing to find someone to date, but nothing ever happens. 
In the control condition, participants visualized a typical date at Miami University and were instructed to write about their visualization of the date.

\section{Jealousy}

Jealousy was measured by examining participants' responses to a mildly jealousy-evoking situation constructed from the items of the Self-Report Jealousy Scale II (SRJS-II; Bringle, 1982) selected based on pretesting with 54 participants (none of whom participated in the current studies). The SRJS-II consists of 25 jealousy-evoking situations with three subscales that assess different levels of jealousyevoking situations: major romantic, minor romantic, and nonromantic. Of those situations, seven were chosen from the minor romantic and major romantic subscales of the SRJS-II that had scores close to the midpoint of the scale, ranging from 1 (very pleased) to 7 (very upset), and that had relatively large variability. A mildly threatening, jealousy-evoking vignette was constructed using these seven items (see Appendix). More specifically, the vignette described a couple attending a party and the participant's current partner consistently interacting with a possible rival to their relationship.

To make the task more engaging and to ensure that participants used their current romantic partner as the subject of the vignette, respondents wrote the first initial of their current partner in several blank spaces throughout the vignette before reading it. After reading the mildly threatening vignette, participants rated the extent to which they would be angry, sad, disgusted, surprised, and worried. In addition, participants were asked if they perceived the event as damaging to the romantic relationship and if they were likely to think about the event after it occurred. The ratings were made on scales ranging from 0 (not at all) to 8 (extremely [for the first five ratings] or all the time [for the latter two ratings]). The scores across the items were averaged to form a measure of jealousy $(\alpha=.89)$, with greater scores indicating more jealousy.

After all of the measures were completed, participants were probed for suspicion, debriefed, and thanked.

\section{Results}

\section{Manipulation checks}

To assess if the manipulation of relationship alternatives was effective, a judge who was unaware of the experimental hypotheses rated how attractive participants' descriptions of the person(s) or date in the visualizations was on a scale ranging from 1 (extremely unattractive) to 7 (extremely attractive). A oneway ANOVA showed that the manipulation of alternative attractiveness was effective, $F(2,57)=170.05, p<.001$. Tukey's HSD post hoc tests showed that the ratings of attractiveness differed significantly between each condition, $p \mathrm{~s}<.001$. Participants' descriptions of the people they envisioned were significantly more attractive in the increase attractiveness of alternatives condition $(M=5.60)$ than in the control condition $(M=3.42)$, which in turn were more attractive than in the decrease attractiveness of alternatives condition $(M=1.45)$. For example, a representative description for the decrease alternatives conditions was, "I would end up dating men that I probably did not find physically attractive and who I did not have a lot in common with. Most likely, I would settle with someone I did not feel attracted to-I would be sad." A representative description for the increase alternatives conditions was, "We'd connect on many levels - emotionally, spiritually, [and] physically. We could talk about anything and our time [together] would be fun. She would be attractive to me without trying to be attractive." Finally, a representative description for the control condition was "The male and female both would be well dressed. Holding hands, while walking uptown to a nice restaurant before going to a late movie."

\section{Commitment and jealousy}

Overall, the level of jealousy in this study was moderate $(M=4.80, S D=1.77)$ and the level of commitment was high $(M=$ $5.99, S D=1.87$ ) as would be expected given that all participants were in serious relationships. The zero-order correlation between 
commitment and jealousy was not significant, $r=.15, n s$. In addition, a one-way ANOVA showed that ratings of commitment did not differ by manipulation of alternatives, $F<1$, indicating that random assignment was effective.

\section{Effects on perceptions of jealousy}

Because an interaction of the manipulation of relationship alternatives and relationship commitment on jealousy was predicted, a multiple regression analysis was conducted. Specifically, the regression compared the relation between commitment and jealousy in the increase alternatives condition to the relation between commitment and jealousy in the decrease alternatives condition.

Centered ratings of relationship commitment, the contrast coefficient (comparing the increase attractiveness of alternatives, coded +1 , to the decrease attractiveness of alternatives condition, coded -1 ), and the interaction of the contrast coefficient and centered ratings of commitment (multiplicative function) were regressed on participants' ratings of jealousy. The multiple $R=.36$ for the regression was significantly different from zero, $F(3,55)=$ $2.81, p<.05, R^{2}=.13$. Importantly, the predicted interaction between commitment and the contrast coefficient made a unique contribution in predicting jealousy, $\beta=-.82, p<$ $.05, R_{\text {change }}^{2}=.07 .^{2}$ Additional follow-up analyses revealed that jealousy and commitment were positively related in the unattractive alternatives condition, $r=.55, p<.02$, but not in the attractive alternatives condition, $r=-.20, n s$. Also, there was no relation between jealousy and commitment in the control condition, $r=.02, n s$. Figure 1 shows that the slopes for the correlations between jealousy and commitment were as predicted for each of the experimental conditions. All figures show how jealousy ( $y$-axis) relates to

2. Although there are other approaches (i.e., $f^{2}$ ), the effect sizes of multiple regression interactions are usually reported in terms of $R^{2}$ change for the interaction term (see O'Connor, 1998 for a review). Thus, this measure of effect size is reported for the significant interactions in the current work.

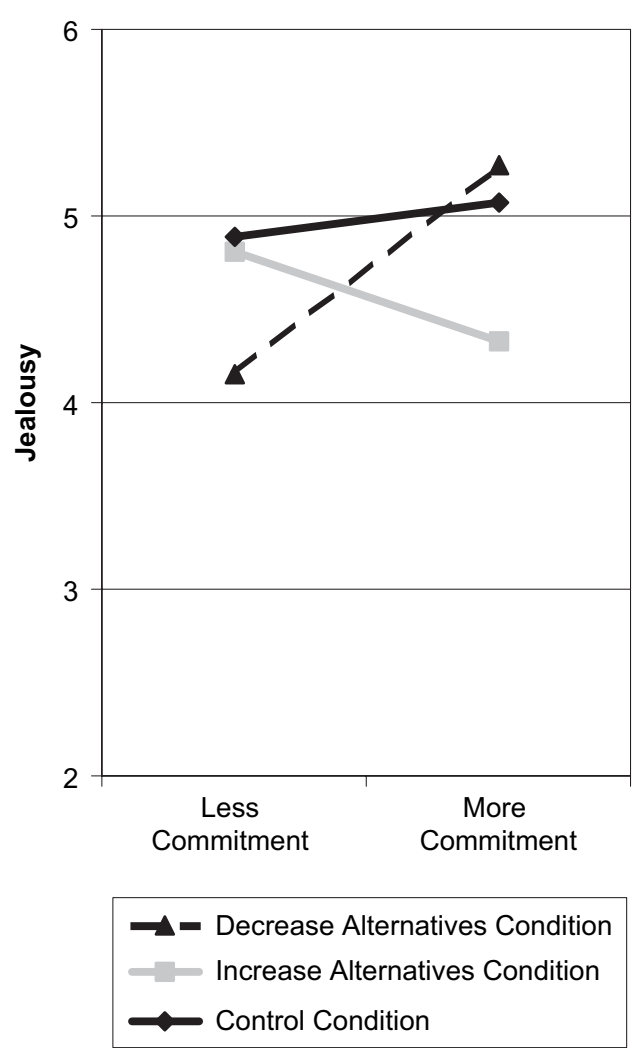

Figure 1. The relation between jealousy and commitment as a function of attractiveness of alternatives condition in Study 1.

commitment plotted at \pm 1 standard deviation from the mean ( $x$-axis), as a function of experimental condition (different lines). The interaction shows that the slopes of the attractive and unattractive conditions differ significantly. Specifically, analyses of correlation $z$-scores, using Fisher's $r$ to $z$ transformation (Cohen \& Cohen, 1983), examined the differences between correlations in the experimental conditions. These analyses showed that the association between commitment and jealousy was significantly greater in the unattractive condition than in the attractive condition, $z=2.00$, $p<.03$, that the association between commitment and jealousy was marginally greater in unattractive condition than in the control condition, $z=1.75, p<.08$, and that the association between commitment and jealousy did not differ between the attractive condition and the control condition, $z=-.61, n s$. 


\section{The role of CLalt}

Because commitment is considered the most important variable in the Investment Model, mediating the relationship between outcomes and other investment model constructs such as CLalt (Le \& Agnew, 2003), it was the focus of the current research. However, one might wonder whether commitment is confounded with CLalt in this study because the attractiveness of possible dating alternatives was manipulated. To statistically rule out CLalt as an alternative explanation for the results concerning commitment, we included the measure of CLalt in the regression predicting jealousy from commitment, the contrast coefficient, and their interaction term. Importantly, CLalt did not attenuate the predicted commitment by contrast coefficient interaction for jealousy, $\beta=-.98, p<.05$, $R_{\text {change }}^{2}=.14$. Thus, CLalt cannot account for the primary findings of interest involving commitment.

\section{Discussion}

The results confirmed transactional and system theories of jealousy (Bringle, 1991; White, 1991), heretofore untested by experimental manipulations. That is, situational factors and relationship factors interacted to facilitate the expression of jealousy. Specifically, perceptions of relationship commitment were positively associated with the expression of jealousy when the respondents had relatively unattractive relationship alternatives accessible. When attractive alternatives were made accessible, there was no association between commitment and jealousy. The study also showed that perceptions of relationship alternatives played a causal role in the relation between level of commitment and jealousy. Thus, these results provide boundary conditions for previous findings that individuals in more committed relationships experience greater jealousy (e.g., Buunk, 1991; Hansen, 1991; White, 1981).

However, one may note that highly committed individuals are less likely than less committed individuals to attend to relationship alternatives (Miller, 1997). Although this has been demonstrated, work on attention to relationship alternatives and commitment also shows that individuals greater in commitment still attend to their alternatives and quite possibly consider the virtues of alternatives spontaneously (e.g., Johnson \& Rusbult, 1989; Thibaut \& Kelley, 1959). Thus, although highly committed individuals may be relatively less preoccupied with alternatives to their current relationship, they are not oblivious to them either. If no attention was paid to alternatives when people are in a committed relationship, how would they know if they should move from their current partner to an alternative partner who could possibly provide them with more positive relationship outcomes? Indeed, researchers have shown that people in committed relationships often compare the virtues of their alternatives to the virtues of their current partner (e.g., Johnson \& Rusbult), whereas other research has shown that people attend equally to relationship alternatives regardless of commitment level (e.g., Simpson, Gangstead, \& Lerma, 1990). And even if highly committed people are less inclined to consider alternatives than less committed individuals, we contend that understanding how people who vary in relationship commitment respond differently to threat is important for examining the processes presumed to underlie interdependence theory.

Although our manipulation of relationship alternatives was effective in producing descriptions of relationship alternatives that were attractive or unattractive, it is possible that this manipulation could have unintentionally manipulated other constructs unrelated to the attractiveness of relationship alternatives. Further, although we predicted that perceiving unattractive alternatives would lead to greater perceptions of threat, we did not measure threat to the self or relationship in this study. To examine potential confounds and to evaluate our reasoning regarding threat, extensive pretesting was conducted on the manipulation of relationship alternatives used in Study 1. Alternative explanations and conceptual issues were examined in four pretests. These pretests had a total of 206 participants in serious relationships (none of whom 
participated in the current studies) who completed the visualization exercise from Study 1. Participants then completed measures of constructs (all of which showed adequate reliability, $\alpha \mathrm{s}>.74)$ that could provide alternative explanations for the results of Study 1 or were important to our presumed role of threat in Study 1. For example, it could be asserted that our manipulation did not manipulate threat but instead manipulated mood or self-esteem. However, the manipulation of alternatives did not affect positive mood or negative mood (Watson, Clark, \& Tellegen, 1988) across the two pretests that assessed mood nor did it affect self-worth (Rosenberg, 1965; Snell \& Finney, 1993) across the two pretests that assessed selfesteem. Thus, it is unlikely that alternative explanations involving changes in mood or self-esteem as a function of our experimental manipulations can account for the results of Study 1.

It could also be argued that the manipulation of alternatives changed participants' perceptions of relationship commitment, thus the perceived relationship commitment level measured before the manipulation may not be equivalent to the perceived relationship commitment level when responding to the jealousy vignette. This does not seem like a plausible alternative because the manipulation of alternatives did not affect level of commitment (Rusbult et al., 1998) across the two pretests that assessed postmanipulation measures of current relationship commitment. Therefore, it is unlikely that participants' level of commitment was affected by the manipulation of alternatives.

Finally, our argument hinges on the supposition that manipulation of alternatives affects perceptions of threat. Indeed, pretesting revealed that the manipulation of alternatives significantly increased perceptions of threat to the relationship in the decrease alternatives condition relative to the increase alternatives or control conditions, indicating that our manipulation did indeed affect threat to the relationship, as desired (however, it did not affect threat to the self). In sum, the results of these four pretests rule out several alternative explanations of our findings for
Study 1 and provide support that relationship threat was affected by the manipulation of relationship alternatives.

Study 1 assumed that individuals who perceived that their relationship was committed and imagined attractive alternatives may not have felt that their relationship or self was threatened, and accordingly did not experience much jealousy, whereas those who perceived that their relationship was committed and imagined unattractive alternatives felt greater threat and thus experienced more jealousy. This suggests that perceptions of threat to the relationship are important for the link between commitment and experiencing jealousy; however, such a connection was not established empirically in Study 1. Study 2 tested this reasoning more directly.

\section{Study 2}

Although Study 1 demonstrated that the accessibility of attractive or unattractive relationship alternatives affected the relation between commitment and the expression of jealousy in a mildly threatening social situation, it did not directly examine whether perceptions of threat also play a causal role in the experience of jealousy.

To examine the process by which commitment and threat affect jealousy, Study 2 manipulated threat directly via false feedback on a computerized "test" of relationship compatibility. Individuals who had more committed relationships and received negative, threatening information about their relationship and the self should be especially likely to experience jealousy. Thus, individuals receiving threatening information about their relationship and self should show a positive relation between relationship commitment and jealousy. However, individuals who receive positive information about their relationship and the self should show little or no relation between their level of relationship commitment and jealousy because they should not perceive threat and thus not feel jealous.

In addition, we were interested in how perceptions of the computerized relationship compatibility test varied as a function of 
level of commitment and type of feedback. In an interesting display of motivated cognition in romantic relationships, Johnson and Rusbult (1989) showed that people in more committed relationships derogated possible relationship alternatives to maintain an overly positive view of their relationship partner. Thus, it was posited that individuals receiving negative information about their relationship and self would be less likely to perceive the relationship compatibility test as valid to the extent that they were greater in commitment. This would allow highly committed people to maintain a more positive view of their relationship by derogating the feedback of the relationship compatibility test. However, individuals receiving positive information about their relationship should perceive that the relationship compatibility test is relatively more valid to the extent that they are greater in commitment, allowing highly committed people to maintain positive illusions in their romantic relationships by accepting information from the relationship compatibility test.

\section{Method}

\section{Participants}

At Miami University, 79 students involved in a serious dating relationship at the time of the study (48 women and 31 men, with a mean age of 19.36 years and a mean relationship duration of 14.84 months) participated to fulfill a course requirement.

\section{Commitment}

As in Study 1, participants first completed a paper version of commitment subscale of the Investment Model Scale (Rusbult et al., 1998; $\alpha=.90)$. Participants then began the rest of the study, which was administered at a computer in an individual room.

\section{Manipulating threat to the relationship and the self}

To manipulate threat, participants were brought into the lab to ostensibly measure their relationship compatibility. Participants answered 26 true-false questions (e.g., "I like my romantic relationship partner's friends.", "My partner's parents fought a lot when he/ she was younger.", "My partner was in other serious relationships before ours.") on the computer that they were told assessed relationship compatibility with their current partner, as well as their general relationship compatibility. Specifically, participants were told

Several researchers at top universities have shown that using this indirect method of measuring relationship compatibility that you are about to complete is just as good as assessing relationship compatibility and predicting relationship outcomes (like marriages and breakups) as a more traditional measure of relationship compatibility would be. In addition, it is also a good measure of your overall relationship compatibility (or how compatible you would be with the average person).

Participants then completed the purported measure of relationship compatibility and were given one of three types of feedback. In the negative information condition, participants were told

Your Results on the Relationship Compatibility Scale: You scored a 2.118 out of 10. These results mean that: Compared to people in the average romantic relationship, you and your partner are highly incompatible and, in addition, it would be difficult for you to find another romantic relationship partner that is compatible with you.

In the positive information condition, participants were given the following feedback:

Your Results on the Relationship Compatibility Scale: You scored an 8.882 out of 10. These results mean that: Compared to people in the average romantic relationship, you are extremely compatible with your current partner and, in addition, you could easily find another romantic 
relationship partner that is highly compatible with you.

In the control condition, participants were not given any feedback about the compatibility of their current relationship or their general level of relationship compatibility.

Participants then rated their agreement with two statements, from Sharpsteen (1995), to assess their perceptions of threat ranging from 1 (not at all threatening) to 9 (extremely threatening). The first item assessed their perception of threat to the relationship ("How threatening is this information for your romantic relationship?"), and the second item assessed their perception of threat to their self-esteem ("How threatening is this to you personally [your sense of selfesteem]?"). In addition, participants completed three statements about the accuracy of the relationship compatibility test they had just completed (i.e., "I think that this test is valid.", "This test was interesting and informative.", "I think this test is accurate."). Because these three items were highly interrelated, they were averaged to assess the extent to which participants perceived the test to be valid $(\alpha=.86)$, on scales ranging from 1 (completely disagree) to 9 (completely agree), with greater scores indicating greater test validity.

\section{Jealousy}

Jealousy was assessed using two different measures. One measure was Buunk's (1997) jealousy scale, which includes assessments of emotional (e.g., "How would you feel if your partner had sexual contact with someone else?"), behavioral (e.g., "It is not acceptable to me if my partner sees people of the opposite sex on a friendly basis."), and cognitive forms (e.g., "I am afraid that my partner is sexually interested in someone else.") of jealousy. Participants answered on 5-point scales ranging from 1 (not at all upset) to 5 (extremely upset) for the emotional jealousy, 1 (not applicable) to 5 (very much applicable) for the behavioral jealousy, and 1 (never) to 5 (very often) for the cognitive jealousy. The 15 items were highly intercor- related, and the mean was computed to produce a measure of relationship jealousy $(\alpha=$ .87 ), with larger scores indicating greater jealousy. Jealousy was also measured using the same vignette-based measure as in Study $1(\alpha=.89)$. There was a significant correlation between the vignette-based measure and Buunk's jealousy scale, $r=.35, p<.001$.

After the experimental measures were completed, participants were probed for suspicion, debriefed, and thanked.

\section{Results}

\section{Manipulation check}

To assess if the manipulation of threat was effective, a one-way ANOVA was conducted on information condition (negative information, positive information, no information) for perceptions of relationship threat and threat to the self. There was a significant effect for perceptions of relationship threat, $F(2,77)=4.37, p<.02$. Specifically, Tukey's HSD post hoc tests revealed that participants in the negative information condition felt more relationship threat $(M=2.38)$ than did those in the positive information condition $(M=1.23)$, with those in the no information condition $(M=1.85)$ not differing significantly from either of these conditions. There was also a significant effect of perceptions of threat to the self, $F(2,77)=$ 7.74, $p<.001$. Tukey's HSD post hoc tests revealed that participants in the negative information condition perceived significantly more threat to the self $(M=3.00)$ than did those in the positive information $(M=1.34)$ or no information conditions $(M=1.64)$, with the latter two conditions not differing from each other. Thus, the manipulation of threat appears to have been effective at inducing mild, but reliably different, perceptions of threat to both the self and to the relationship.

\section{The effect of information condition}

The effect of information condition on jealousy, commitment, and perceptions of the test's accuracy was assessed using one-way 
ANOVAs. The results for jealousy showed a no effect of information condition, $F(2,77)$ $=1.46, n s$. In addition (showing that random assignment was effective), ratings of commitment did not differ as a function of the manipulation of threat, $F<1$. However, the effect of information condition did have a significant effect on perceptions of test accuracy, $F(2,77)=17.50, p<.001$. Specifically, Tukey's HSD post hoc tests revealed that the participants in the no information condition and positive information conditions perceived that the test was more accurate $(M=5.62$ and 5.89 , respectively) than those in the negative information condition $(M=3.47)$.

\section{Jealousy and commitment}

Overall, the level of jealousy as measured by Buunk's jealousy scale was moderate $(M=2.71, S D=.65)$ in this study as was the level of jealousy as measured by the vignette $(M=4.78, S D=1.89)$. As in Study 1 , the overall level of commitment was high $(M=5.30, S D=1.96)$. In addition, zeroorder correlations between jealousy, commitment, and perceptions of the test's accuracy (overall $M=5.00, S D=1.98$ ) were calculated. Commitment was not correlated to Buunk's measure of jealousy or the vignettebased measure of jealousy, $r=.18, n s$, and $r$ $=.25, n s$, respectively, nor were perceptions of the test's accuracy related to Buunk's jealousy measure or the vignette measure, $r=.00, n s$, and $r=.07, n s$, respectively.

\section{Effects on perceptions of threat and commitment on jealousy}

To test the critical prediction of an interaction between feedback condition and relationship commitment on jealousy, a multiple regression analysis was conducted. Specifically, the regression compared the relation between commitment and jealousy in the positive information condition to the relation between commitment and jealousy in the negative information condition.

Centered ratings of relationship commitment, the contrast coefficient (comparing the positive information condition, coded +1 , to the negative information condition, coded -1 ), and the interaction of the contrast coefficient and centered ratings of commitment (multiplicative function) were regressed on participants' ratings of jealousy based on Buunk's jealousy scale. The multiple $R=.35$ for this regression was significantly different from zero, $F(3,72)=3.37, p<.03, R^{2}=.12$. Importantly, the predicted interaction between commitment and the contrast coefficient made a unique contribution in predicting jealousy on Buunk's scale, $\beta=.62, p<.05$, $R_{\text {change }}^{2}=.05$. This interaction revealed that jealousy and commitment were positively related in the negative information condition, $r=.51, p<.02$, whereas there was no correlation between jealousy and commitment in the positive information condition, $r=-.08$, $n s$. In addition, there was no correlation between jealousy and commitment in the control condition, $r=.11, n s$. Figure 2 shows


Figure 2. The relation between Buunk's measure of jealousy and commitment as a function of information condition in Study 2. 
that the slopes for the correlation between Buunk's measure of jealousy and commitment were as predicted for each of the experimental conditions. Again, analyses of correlation $z$-scores showed that the association between commitment and jealousy was significantly greater in the negative information condition than in the positive information condition, $z=2.75, p<.01$. No other slopes were reliably different from each other.

When the same multiple regression analysis was conducted for the vignette-based measure of jealousy that was used in Study 1, identical results were observed. The multiple $R=.38$ for this regression was significantly different from zero, $F(3,72)=3.94, p<.02$, $R^{2}=.14$. The interaction term between commitment and the contrast coefficient was significant, $\beta=.78, p<.02, R_{\text {change }}^{2}=.08$. The correlation between commitment and jealousy was positive and significant in the negative information condition, $r=.41, p<$ .05 , was negative but nonsignificant in the positive information condition, $r=-.34$, $p<.13$, and nonsignificant in the control condition, $r=.06, n s$. Figure 3 shows that the slopes for the correlation between the vignette measure of jealousy and commitment were as predicted for each of the experimental conditions. Using Fisher's $r$ to $z$ transformations, the slopes of the negative information condition differed from those of the positive information condition, $z=2.46$, $p<.01$. No other reliable differences were observed between other conditions.

\section{Perceptions of the relationship compatibility test}

Two other multiple regression analyses were conducted. The first analyses conducted were identical to the multiple regression analyses for predicting jealousy except that perception of the validity of the relationship compatibility test was included as an independent variable. The interaction of commitment and the contrast coefficient continued to predict Buunk's measure of jealousy and the vignette measure of jealousy after including the test validity variable, $\beta=.75, p<.03, R^{2}$ change
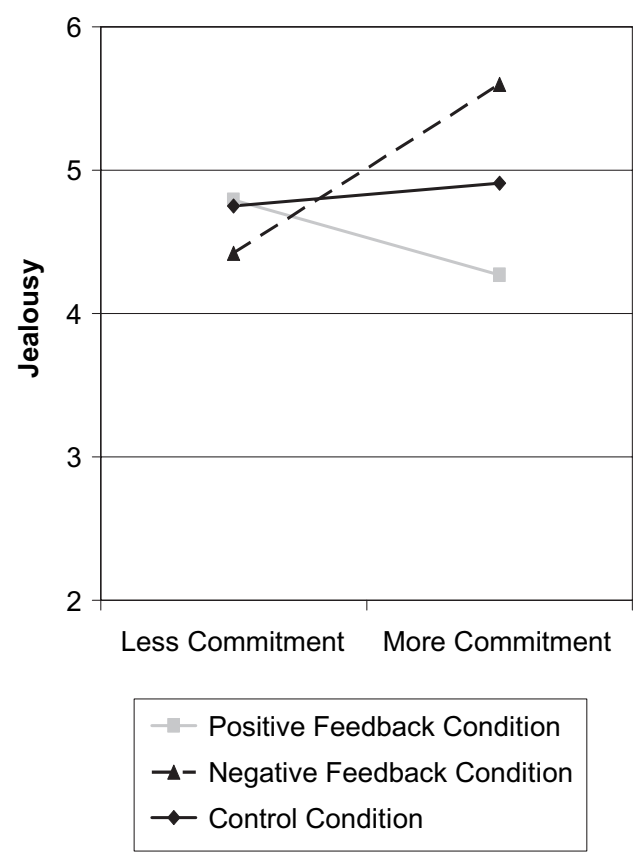

Figure 3. The relation between the vignettebased measure of jealousy and commitment as a function of information condition in Study 2.

$=.07$, and $\beta=.86, p<.01, R_{\text {change }}^{2}=.09$, respectively. This shows that differences in the evaluation of the relationship compatibility test cannot account for the effect of perceptions of threat and relationship commitment on jealousy.

The second regression equation used the same regression analyses as those for jealousy; however, perceptions of the validity of the relationship compatibility test was the criterion variable (with commitment, experimental condition contrast, and their interaction term as the predictors). Consistent with Johnson and Rusbult's (1989) findings, this regression demonstrated that individuals in more committed relationships were more likely to derogate the test when receiving negative (vs. positive) information about their relationship. The multiple $R=.55$ for this regression was significantly different from zero, $F(3,72)=10.29, p<.02, R^{2}=.30$. Specifically, the interaction of commitment and the contrast coefficient predicted the evaluation of the relationship compatibility 
test's validity, $\beta=-.68, p<.02, R_{\text {change }}^{2}=$ .06. The correlation between relationship commitment and the evaluation of the relationship compatibility test's validity was somewhat, though not reliably, negative in the negative information condition, $r=-.30$, $p<.15$, but significantly positive in the positive information condition, $r=.51, p<.02$. In addition, the correlation between relationship commitment and the evaluation of the relationship compatibility test's validity was nonsignificant in the no information condition, $r=-.16, n s$. Moreover, analyses of correlation $z$-scores, using Fisher's $r$ to $z$ transformation, showed that the association between commitment and evaluation of the relationship compatibility test's validity was significantly different between the positive and negative information conditions, $z=2.71$, $p<.01$. These analyses also showed that the association was similar in the negative information condition and the control condition, $z=-.52, n s$, and that the association between commitment and evaluation of the relationship compatibility test's validity differed significantly between the positive information condition and the control condition, $z=2.44, p<.01$. Thus, when participants were in more committed relationships and given negative information about their relationship compatibility, they were more likely to derogate the compatibility test than those who had committed relationships and were given positive feedback. This extends the work of Johnson and Rusbult by showing that individuals were more likely to accept or derogate the validity of the instrument that purportedly measured aspects of their romantic relationship, suggesting that acceptance or derogation may have served to maintain a positive view of their relationship when individuals are more committed to their relationships. However, these findings differ from those of Simpson et al. (1990), who found that individuals in all types of dating relationships (e.g., casually dating, seriously dating, engaged, married) derogated alternatives. Regardless, these findings suggest that the results for jealousy (i.e., the commitment by threat interactions) were robust because they were obtained despite data suggesting that positive relationship illusions may have been utilized. That is, despite data suggesting that people engaging in motivated reasoning for the compatibility test, the feedback was still impactful (as evidenced by differences in perceptions of threat), and it had causal implications for those greater in commitment experiencing greater jealousy (on both measures of jealousy used in Study 2).

\section{Discussion}

Study 2 showed that individuals who had their relationship and self threatened were more likely to express jealousy when they were more committed to their relationships, whereas those who did not have their self or relationship threatened showed no relation between relationship commitment and jealousy. These findings are consistent with the presumed underlying role of threat in Study 1 but empirically established the importance of threat in the link between relationship commitment and the expression of jealousy. Study 2 provided the first experimental support for the supposition that individuals who are in more committed relationships and experience threat are more likely to react jealously than those who are in committed relationships but are not threatened (e.g., Bringle, 1991; Buunk, 1991; Buunk \& Bringle, 1987; White \& Mullen, 1989). Although, it may be noted that the overall amount of threat induced in this study was relatively mild, our experimental manipulation did produce reliable differences in perceptions of threat that in turn impacted the experience of jealousy. Although inducing stronger threat would have been preferable, it is not necessarily easy to produce large differences in perceptions of threat when competing against a participant's lifetime of personal experiences and relationship experiences that could be drawn upon. But more important, experimentally manipulating threat in the current study (even if such manipulations are relatively modest in nature) allowed us to assess the causal relations presumed to underlie the experience of jealousy.

Although our manipulation of relationship compatibility was effective in producing threat to the self and relationship, it is possible 
that this manipulation could have unintentionally manipulated constructs unrelated to threat. To examine if the manipulation of relationship compatibility affected mood and self-esteem (which might serve as alternative explanations for the role of threat in the current study), 40 participants in serious relationships (none of whom participated in the current studies) first completed the manipulation of relationship compatibility on a computer and then completed measures of self-esteem ( $\alpha=.81$; Rosenberg, 1965) and measures of positive affect and negative affect $(\alpha=.82$ and $\alpha=.74$, respectively; Watson et al., 1988). The manipulation of relationship compatibility did not produce any reliable differences on these measures. Thus, alternative explanations involving selfesteem or mood are unlikely to explain the results of Study 2.

In addition, one may also ask if the relationship compatibility test was just seen as less believable and that lower evaluations of its validity were not really indicative of derogating the test. It is important to note, however, that if the test was truly seen as invalid, derogation would not follow from the negative feedback, and more important, threat would not be significantly greater for those who received negative feedback than for those who received positive feedback. Clearly, this was not the case in Study 2. Thus, derogation of the test appears to have occurred without the test being seen as nondiagnostic of one's relationship compatibility.

\section{General Discussion}

The current work demonstrated that the appraisal of threat plays an important role in the experience of jealousy. Study 1 found that those with more committed relationships experienced greater jealousy in a mildly threatening situation when they felt that they had relatively unattractive alternatives. Study 2 extended these findings by demonstrating the causal role of threat in the link between relationship commitment and jealousy. The results of the two studies were quite similar even though they used different manipulations of threat and more than one measure of jealousy.
The role of threat in facilitating the expression of jealousy in romantic relationships has long been suggested (Salovey, 1991; White \& Mullen, 1989) and supported by correlational (e.g., Radjecki-Bush et al., 1993; White, 1981) and empirical research (Bush et al., 1988; Sharpsteen, 1995). However, the current work demonstrated that individuals who have more committed romantic relationships were more likely to react jealously to threatening information than individuals who had less committed relationships. Thus, both studies provided causal evidence for important moderators in the link between relationship commitment and the expression of jealousy.

Moreover, this research demonstrated the importance of theoretical conceptualizations that emphasize the interaction of factors internal and external to the romantic relationship in facilitating the expression of jealousy (e.g., Bringle, 1991; White, 1991; White \& Mullen, 1989). Past research found support for the role of only external factors (i.e., the level of threat to the self and to the relationship or jealousy threat; e.g., Bush et al., 1988; DeSteno \& Salovey, 1996; Sharpsteen, 1995) or only internal factors (e.g., Buunk, 1991) in facilitating jealousy. However, the current work extends this previous research by showing that internal and external factors interact to facilitate the expression of jealousy (e.g., Bringle, 1991). For example, Sharpsteen found that individuals who experienced threat to the self and to the relationship, by reading about jealousy-evoking situations, were more likely to experience jealousy. However, the current work demonstrates that commitment to one's romantic relationship moderates this effect. DeSteno and Salovey found that rivals who were perceived as similar and more threatening to the self were more likely to evoke jealousy. The current work extends this research on jealousy-evoking aspects of rivals by suggesting that individuals who are in more committed relationships should view aspects of a similar rival as more threatening to the self, and thus, more jealousy evoking.

Bush et al. (1988) showed that individuals who imagined themselves in highly jealousyevoking situations (e.g., your partner spends 
increasing time with an old girl/boyfriend and appears to be getting close to her/him again) were more likely than individuals who imagined themselves in mildly jealousyevoking situations (e.g., your partner remarks to you that they find another male/female attractive) or innocuous situations to express an array of negative responses (e.g., jealousy, fear, surprise, distress, anger). They also measured love and examined the interaction of love and their imagination task in predicting jealousy and other emotions. Bush et al. found that individuals with "greater love for their partners reported higher levels of relationship jealousy in response to imagery scenes" (p. 296). Thus, regardless of imagery condition, there was a positive relation between love and relationship jealousy. However, the interactions of love and the imagery task demonstrated that individuals who imagined themselves in highly jealousy-evoking situations showed a positive relation between love and feeling more frightened in response to the imagery task and believing that one is more involved in the relationship than the partner. The current research differs from Bush et al.'s and Sharpsteen's (1995) work because it looks at the interaction of commitment and situational variables not related to imagining jealousy-evoking situations or rivals. Instead, it manipulated perceptions of alternative relationship attractiveness and relationship compatibility to understand the links between threat, commitment, and jealousy.

Although the manipulations of alternative attractiveness and relationship threat were carefully designed to examine the how factors internal and external to the relationship affect the expression of jealousy, attributes of the person, relationship, and situation vary and should influence the expression of jealousy (e.g., Bringle, Renner, Terry, \& Davis, 1983). It is important to understand that variability in these components of the romantic relationship has implications for relationship outcomes, especially because the current research only examined commitment at one point in time.

Nonetheless, the current work makes important contributions by empirically establishing some of the factors that facilitate the expression of jealousy in close relationships, and future work on jealousy should continue to explore the interaction of both internal and external variables to romantic relationships in understanding relationship judgments (e.g., Bringle, 1991; Levinger, 1976; White \& Mullen, 1989). For instance, examining the effect of manipulating perceptions of commitment (e.g., Finkel, Rusbult, Kumashiro, \& Hannon, 2002) on jealousy would be beneficial because it would provide causal evidence that increasing commitment facilitates greater expression of jealousy. Those who have more committed relationships differ psychologically in many important ways from those who do not (e.g., Kelley, 1979), and future research should work to untangle the different causal roles of threat from personality factors that might mediate the link between commitment and jealousy.

In addition to examining self-reported jealousy as an outcome, future work should also examine relationship-related behaviors that result from feeling jealous. For example, under what conditions does jealousy lead to the dissolution of the relationship (e.g., Mathes, 1986) or to further investments in the current relationship (e.g., White, 1980)? The current work suggests that those who follow the latter path may set themselves up for even stronger jealous responses in the future if relationship threat persists because of increasing commitment to the current romantic relationship. This increase in commitment should facilitate the expression of jealousy because individuals who feel that they have more to lose and perceive that their relationship is threatened should be more likely to express jealousy; however, it is important to note that external norms (e.g., Buunk, 1991) or personality factors (e.g., attachment style; Radjecki-Bush et al., 1993) may moderate the expression of jealousy.

Ironically, but related to this line of reasoning, people in more committed relationships may be less likely to express jealous behaviors (e.g., monitoring the partner), but they also show greater emotional upset when confronted with a jealousy-evoking event (e.g., Bringle, 1991; White, 1981). People in less committed relationships do not have 
much to lose by the dissolution of the relationship (they have not invested much into the relationship), whereas people in committed relationship have invested heavily in their relationships. One reason why people who are in more committed relationships may feel jealous but respond in less destructive ways to those feelings is to preserve a relationship in which they have invested heavily (e.g., Rusbult et al., 1991). It is one thing to be jealous, but jealousy can be expressed in many ways (e.g., Bringle). Jealousy can even serve to strengthen the relationship. For example, Mathes (1986) found that couples who had greater levels of jealousy were more likely to be together and to be married 5 years after the initial assessment of jealousy. Thus, jealousy can serve many positive functions in relationships and can serve to make relationships more committed (White, 1980).

\section{Limitations}

Although we believe that this research advances our understanding of jealousy, there are some important limitations to this work. As mentioned earlier, the amount of threat induced by our manipulation in Study 2 was modest, and it is unclear if people who are facing extreme threat would differ in jealousy as a function of commitment. It could be that people who are extremely threatened would respond jealously regardless of the commitment level in their current relationship. In addition, although we have evidence that our manipulation in Study 1 manipulated the attractiveness of the alternatives that people visualized, it is clear that other approaches that provide converging evidence for the manipulations of alternative attractiveness would offer even greater support for these claims. Further, this research did not manipulate threat to the self and threat to the relationship orthogonally. Although past research has shown that threats to both the relationship and the self were more likely to produce jealousy (Sharpsteen, 1995), we cannot speak to their independent contributions in our research. Thus, future work should address if manipulating threat to the self or threat to the relationship is more likely to produce jeal- ousy when people are more committed to their relationship. We would emphasize that our research was not intended (nor able) to examine if threat to the relationship and threat to the self affect jealousy through the same or different mechanisms; however, we did show that the interaction of overall threat (broadly defined) and commitment was important to understanding jealousy.

\section{Conclusion}

In sum, this research goes beyond the correlational approach used in most of the previous work to examine how situational factors interact with relationship factors to produce jealousy. Specifically, manipulating the attractiveness of relationship alternatives affected the relation between commitment and jealousy. Differences in perceptions of threat were presumed to underlie this effect, and Study 2 demonstrated that manipulating perceptions of threat moderated the link between commitment and the expression of jealousy. Thus, the current work confirmed that factors external and internal to the relationship interact to facilitate the expression of jealousy. Because this supposition is central to many influential theories of jealousy (e.g., Bringle, 1991; Buunk \& Bringle, 1987; DeSteno \& Salovey, 1996; White, 1991; White \& Mullen, 1989), this research adds to our understanding by revealing that the interaction of situational and relationship factors is important for understanding the causes of jealousy. Close personal relationships, arguably, is one of the most important yet most complex topics in personality and social psychology. The interplay between internal and external factors demonstrated in the current work reaffirms this intricacy. Because relationships are an important factor of human experience, it is sensible that threat, whether instantiated by unattractive alternatives or by negative feedback about one's relationship efficacy, should encourage jealousy in more committed relationships. By exploring these issues experimentally, the current work begins to shed light on the causal mechanisms for one of the most central phenomena experienced in romantic relationships. 


\section{References}

Agnew, C. R., Van Lange, P. A. M., Rusbult, C. E., \& Langston, C. A. (1998). Cognitive interdependence: Commitment and the mental representation of close relationships. Journal of Personality and Social Psychology, 74, 939-954.

Bringle, R. G. (1982). Preliminary report on the SelfReport Jealousy Scale. Unpublished manuscript.

Bringle, R. G. (1991). Psychosocial aspects of jealousy: A transactional model. In P. Salovey (Ed.), The psychology of jealousy and envy (pp. 103-131). New York: Guilford.

Bringle, R. G., Renner, P., Terry, R., \& Davis, S. (1983). An analysis of situational and person components of jealousy. Journal of Research in Personality, 17, 354-368.

Bush, C. R., Bush, J. P., \& Jennings, J. (1988). Effects of jealousy threats on relationship perceptions and emotions. Journal of Social and Personal Relationships, 5, 285-303.

Buss, D. M. (1994). The evolution of desire: Strategies of human mating. New York: Basic Books.

Buss, D. M. (2000). The dangerous passion: Why jealousy is as necessary as love and sex. New York: Free Press.

Buunk, B. P. (1982). Anticipated sexual jealousy: Its relationship to self-esteem, dependency and reciprocity. Personality and Social Psychology Bulletin, 8, 310-316.

Buunk, B. P. (1991). Jealousy in close relationships: An exchange-theoretical perspective. In P. Salovey (Ed.), The psychology of jealousy and envy (pp. 148-177). New York: Guilford.

Buunk, B. P. (1997). Personality, birth order and attachment styles as related to various types of jealousy. Personality and Individual Differences, 23, 997-1006.

Buunk, B. P., \& Bringle, R. G. (1987). Jealousy in love relationships. In D. Perlman \& S. Duck (Eds.), Intimate relationships: Development, dynamics, and deterioration (pp. 123-147). Thousand Oaks, CA: Sage.

Cohen, J., \& Cohen, P. (1983). Applied multiple regression/correlation analysis for the behavioral sciences. Hillsdale, NJ: Erlbaum.

DeSteno, D., \& Salovey, P. (1996). Jealousy and the characteristics of one's rival: A self-evaluation maintenance perspective. Personality and Social Psychology Bulletin, 9, 920-932.

Finkel, E. J., Rusbult, C. E., Kumashiro, M., \& Hannon, P. (2002). Dealing with betrayal in close relationships: Does commitment promote forgiveness? Journal of Personality and Social Psychology, 82, 956-974.

Hansen, G. L. (1991). Jealousy: Its conceptualization, measurement, and integration with family stress theory. In P. Salovey (Ed.), The psychology of jealousy and envy (pp. 211-230). New York: Guilford.

Hupka, R. (1991). The motive for arousal of romantic jealousy: Its cultural origins. In P. Salovey (Ed.), The psychology of jealousy and envy (pp. 252-270). New York: Guilford.

Johnson, D. J., \& Rusbult, C. E. (1989). Resisting temptation: Devaluation of alternative partners as a means of maintaining commitment in close relationships. Journal of Personality and Social Psychology, 57, 967-980.

Kelley, H. H. (1979). Personal relationships: Their structure and processes. Hillside, NJ: Erlbaum.
Le, B., \& Agnew, C. R. (2003). Commitment and its theorized determinants: A meta-analysis of the Investment Model. Personal Relationships, 10, 37-57.

Levinger, G. (1976). A social psychological perspective on marital dissolution. Journal of Social Issues, 32, $21-47$.

Mathes, E. W. (1986). Jealousy and romantic love: A longitudinal study. Psychological Reports, 58, 885886.

Mathes, E. W., \& Severa, N. (1981). Jealousy, romantic love, and liking: Theoretical considerations and preliminary scale development. Psychological Reports, 49, 23-31.

Miller, R. S. (1997). Inattentive and contented: Relationship commitment and attention to alternatives. Journal of Personality and Social Psychology, 73, 758-766.

O'Connor, B. P. (1998). SIMPLE: All-in-one programs for exploring interactions in moderated multiple regression. Educational and Psychological Measurement, 58, 833-837.

Radjecki-Bush, C., Farrell, A. D., \& Bush, J. P. (1993). Predicting jealous responses: The influence of adult attachment and depression on threat appraisal. Journal of Social and Personal Relationships, 10, 569-588.

Rosenberg, M. (1965). Society and the adolescent selfimage. Princeton, NJ: Princeton University Press.

Rusbult, C. E. (1980). Commitment and satisfaction in romantic associations: A test of the investment model. Journal of Experimental Social Psychology, 16, 172-186.

Rusbult, C. E. (1983). A longitudinal test of the investment model: The development (and deterioration) of satisfaction and commitment in heterosexual involvements. Journal of Personality and Social Psychology, 45, 101-117.

Rusbult, C. E., Martz, J. M., \& Agnew, C. R. (1998). The investment model scale: Measuring commitment level, satisfaction level, quality of alternatives, and investment size. Personal Relationships, 5, 357-391.

Rusbult, C. E., Verette, J., Whitney, G. A., Slovik, L. F., \& Lipkus, I. (1991). Accommodation processes in close relationships: Theory and preliminary empirical evidence. Journal of Personality and Social Psychology, 60, 53-78.

Salovey, P. (Ed.). (1991). The psychology of jealousy and envy. New York: Guilford.

Sharpsteen, D. J. (1995). The effects of relationship and self-esteem threat on the likelihood of romantic jealousy. Journal of Social and Personal Relationships, $12,89-101$.

Shettel-Neuber, J., Bryson, J. B., \& Young, L. E. (1978). Physical attractiveness of the "other person" and jealousy. Personality and Social Psychology Bulletin, 4, 612-615.

Simpson, J. A., Gangstead, S. W., \& Lerma, M. (1990). Perception of physical attractiveness: Mechanisms involved in the maintenance of romantic relationships. Journal of Personality and Social Psychology, 59, 1192-1201.

Snell, W. E., Jr., \& Finney, P. D. (1993). Measuring relational aspects of the self: Relationship relationalesteem, relational-depression, and relational-preoccupation. Contemporary Social Psychology, 17, 44-55.

Thibaut, J. W., \& Kelley, H. H. (1959). Social psychology of groups. New York: Wiley.

Watson, D., Clark, L. A., \& Tellegen, A. (1988). Development and validation of brief measures of positive 
and negative affect: The PANAS scales. Journal of Personality and Social Psychology, 54, 1063-1070.

White, G. L. (1980). Inducing jealousy: A power perspective. Personality and Social Psychology Bulletin, 6, 222-227.

White, G. L. (1981). Relative involvement, inadequacy, and jealousy: A test of a causal model. Alternative Lifestyles, 4, 291-309.

\section{Appendix}

I have been dating “ " for a while now.

We both like to attend parties with our friends quite frequently. Lately, “ " has been going to parties without me, in fact, "__ has generally been doing more activities (like hanging out with friends) without me; however, last Friday we both went to a party at a mutual friends' house. Our mutual friend, J. T., has a new house that was rented at a really great price. I could not believe how excited J. T. was to give me a tour of the new place. When I was finished with my tour of the downstairs, I saw “ " involved in a lively, and by the looks of it very entertaining, conversation with a person of the opposite sex who I didn't know. Just before I went
White, G. L. (1991). Self, relationship, friends, and family: Some applications of systems theory to romantic jealousy. In P. Salovey (Ed.), The psychology of jealousy and envy (pp. 231-251). New York: Guilford.

White, G. L., \& Mullen, P. E. (1989). Jealousy: Theory, research, and clinical strategies. New York: Guilford.

upstairs to finish my tour, I saw " and this person start to hug. "“ " later told me that the person is a friend from class that "_ " has done a lot of class work with. Everyone had a good time listening to music and talking. I did a lot of dancing that night so I decided to get some fresh air and talk to some of my friends on the porch. While I was outside I looked in the window and saw "__ " and the person from class dancing together and laughing. Before we left the party, "__ " had to go back to say good-bye to the person from class. On the way home "__ " talked the whole time about the person from class. "__ " thought that we would really hit it off. 